\title{
4 \\ Everyday cyborgs and the love-hate cybernetic relationship
}

\section{Introduction}

The term cyborg rarely appears in the sociology of health or medicine literature and seems never used about people who live with technological modifications as a form of therapy. This is a curious absence (the absence itself rarely commented upon) given the increasing reliance on cybernetic technologies by Western medical professionals in economically developed societies. Reluctance to use the term cyborg more generally is related to the widespread knowledge of the cyborg in extremis; the inhumane, often male, monsters depicted in modern science-fiction, horror and popular media. They lose their human identity via a loss of humanity through the additions of cybernetic biotechnologies to their human forms (Oetler, 1995). The term cyborg, as discussed in the last chapter, however, was first introduced in the 1960s, predicting a need for closed-loop feedback mechanisms to regulate body responses during future space travel (Clynes and Kline, 1960). Such technological modifications did not change the male space traveller. Science and technology scholars and feminists reinvigorated the cyborg, and Donna Haraway's influential conceptualisation of the cyborg is of a liberating figure that is ahistorical and post-gender, which is why it can offer an ability to liberate from classificatory dualist categories (1991). As I shall outline in this chapter, the everyday versions of the cyborg have little in common with the science-fiction cyborg apart from being male living as a techno-organic hybridity. Then everyday cyborgs are modified but not enhanced by their technological modifications; their emotions and feelings are not suppressed but heightened. As most psychological studies conducted with ICD patients show, 
there is a high prevalence of anxiety, depression and even anger in the ICD population. ICDs can cause cyborgs and their significant others emotional, physiological, psychological and social challenges that are rarely made visible. A cyborg individual or cyborg group identification thus reawakens interest in the techno-organic hybrid condition leading to new understandings about the obstacles as well as the benefits that implants pose.

By identifying and defining the everyday cyborg population, we begin to see how it affects the individual and their significant others. Re-appropriating the term cyborg for the everyday, as I will go on to show, reinserts issues about: what cyborgs need to live happy and fulfilling lives; what kind of support they and their significant others might find useful; as well as what type of information and understanding is required to acclimatise to a new techno-organic coalition. At the very minimum, the ICD offers a safety net, an umbrella to shelter them from death by SCA. This dependency invokes new vulnerabilities, as ICD and other implantable medical technologies are often out of reach of immediate human intervention and control. Becoming cyborg and an essential part of the cyborgisation process is not about changing subjectivity through the alteration of materiality that organic transplants cause through contamination. Unlike contamination reported from organic hybrids in previous chapters, the techno-organic hybrids experience technological invasion and device alienation. Then specific obstacles to the everyday cyborgs relate acclimatisation to a new hybridity that is initially alienating. Acclimatisation is a process whereby the ICD, experienced as an alien invader, becomes a part of their lives and their body. For everyday cyborgs with ICDs, their lives depend on the technology's autonomous functioning and this may be just as much a challenge as the ICD malfunctioning.

\section{Finding and talking with the everyday cyborgs}

I set out to find and talk with the everyday cyborgs. To me, it appeared crucial that the story of the ICD and cyborgisation had to be told from the cyborg's standpoint. To do so, I required the assistance of those involved in their creation and follow-up. In 2014, this research with everyday ICD cyborgs and significant others 
gained NHS ethical approvals, and participants were recruited using NHS gatekeepers through a consent-to-consent approach. Cardiac surgeons and electrophysiologists who create and maintain the everyday cyborgs identified and approached them on my behalf with information about the study and a consent form to return to me. I have no way of telling, therefore, which everyday cyborgs were approached by them and which refused to take part in this study. Of the 21 that agreed to participate, four everyday cyborgs were 'new', having received their ICDs in the six months before being interviewed. All of the new everyday cyborgs agreed to a repeat interview after a year, so that we could reflect on their experiences. This strategy offered a reflection on the accounts they had given a year previously, and also an updated one on what had changed in their life. These 'then and now' accounts they had given could be compared to the accounts of the older everyday ICD cyborgs when talking about their periods of transition to a cyborg life. A few of the older generation everyday cyborgs were now living with their second ICD system as the devices are replaced after approximately eight years depending on their activity levels. These older everyday cyborgs had lived a techno-organic hybrid existence for many years; some were living longer as an everyday cyborg than as a non-cyborg human.

I met with the 21 everyday cyborgs who agreed to take part in interviews. Interviews usually took place at their home but sometimes in a café or at the hospital after routine clinic checkups. Before the meeting, I suggested they might want to invite others to be present and sent an additional consent form to give to them and sign. This invitation served the purpose of offering extra support when talking about the cyborgisation process, and if they felt inclined, they could share their thoughts and experiences. Wives, husbands or partners joined in 13 of the interviews, having completed an additional consent form. Occasionally, daughters, sons-in-law and grandchildren were present and contributed to the narratives. Generally, the presence of another person was supportive and helped the everyday cyborg recollection of events and enriched them with their perspective. However, it may have affected what the everyday cyborg was prepared to say in front of others this appeared to be the case, for example, in Ramsay's interview when his wife Fay was present as I will show later. 
Interviews were generally open-ended and flexible and could last from an hour to three hours. In the discussion, we covered areas such as: the circumstances up to and including the decision to implant the ICD; the experience of having one implanted; challenges and benefits of ICDs as well as thoughts more generally, about how it had affected their life, including views of the ICD firing or not. In some cases, we ended with discussing whether they would want or had thought about the removal of the ICD. Broaching death, dying and the ICD was extremely difficult and I erred on the side of caution by not raising it unless I was sure it would not upset anyone. Interestingly, this may be a reason why only a few of the everyday cyborgs recalled having a conversation with a health professional about removal as I go on to discuss later. That is, because they may have attempted to avoid unnecessarily upsetting the everyday cyborg.

Interviews were recorded, transcribed verbatim and then analysed, influenced by grounded theory and using an iterative approach to organising the transcripts, generating the codes, analysing the coding, and comparing themes in and between the coding sections of the interviews. This process was aided with the usage of the software package Nvivo 11. In the following accounts, I have kept as per participant wishes, their first names or a pseudonym they suggest. I have chosen to keep the Scottish vernacular and phrases in the quotes I use because, as I have emphasised, these are their stories and therefore should be told in their way and their own words.

\section{Naming the cyborg?}

During the interviews, I did not specifically ask the participants whether they identified themselves as a cyborg or not. This was for numerous reasons. Partly, the frequent equation of cyborgs (organic-technological hybrids) with androids (robots in human form) and robots (no organic or living parts) made it difficult to tell what exactly was being referred to (e.g. in the survey results there appeared to be little distinction being drawn by the respondents). The cultural baggage the term carries relating to the pervasiveness of the horror or science-fiction 'cyborg-as-monster' as I discussed 
in the previous chapters made it unlikely anyone would identify as such. Indeed, none of the everyday cyborgs apart from one mentioned the term 'cyborg' spontaneously to describe himself, and he thought it a description only he could use and was not to be used by others to describe him. Researching the term 'cyborg' made me realise that the conflation of the cyborg-as-monster with the everyday cyborg will be a significant and on-going issue.

This caused me to think carefully about what benefit using such a controversial term would offer, for example, discussing individual vulnerability as well as the stratification in cyborgisation as a form of 'cyborg sexism'.

\section{Who are the everyday cyborgs?}

Three everyday cyborgs were women, and 18 were men with ages ranging from 32 to 82 at the time of interview. This reflects the gender distribution of ICD implantation in the US and UK that is heavily weighted towards men. However, it does not follow (and nor would I claim) that the following findings are representative of all individuals; only that it appears to reflect general demographics regarding gender distribution.

Eleven had survived an SCA (see Table 4.1 below) and ten had suffered a heart attack and were thought likely to have a sudden cardiac episode. Some had genetic conditions that indicated they had a high risk of SCA, such as Brugada syndrome, arrhythmogenic right ventricular cardiomyopathy (ARVC), or Long-QT syndrome, and therefore were given an ICD for prophylactic reasons. For one or two of the individuals I interviewed, the cause of the sustained arrhythmias or arrest remained unknown. There appeared to be stress or 'heart-ache' in the family of the everyday cyborgs. There is on-going research into a condition called 'Takobutso Syndrome', or stress cardiomyopathy, that a person might experience after a devastating loss (although I am not suggesting that this was the case for these people who had an SCA with no explanation).

Eleven had reported never experiencing a shock. Six had been shocked once, and five had experienced shocks from their ICDs on several occasions. Two had received consecutive shocks, on the 
same occasion known as 'storms' (see Table 4.1 Demographics of everyday cyborgs). As I demonstrate, however, it was challenging to tally whether the ICD had fired or not with the experience of

Table 4.1 Demographics of everyday cyborgs

\begin{tabular}{|c|c|c|c|c|c|c|}
\hline & Gender & $\begin{array}{l}\text { Age } \\
\text { group }\end{array}$ & $\begin{array}{l}\text { Marital } \\
\text { status }\end{array}$ & $\begin{array}{l}\text { How long } \\
\text { ICD }\end{array}$ & Firings & SCA \\
\hline 1 Alfred & Male & $61-70$ & Married & over 5 yrs & Multiple & Yes \\
\hline 2 Audrey & Female & over 70 & Married & under 6 mths & Once & Yes \\
\hline 3 David & Male & $41-60$ & Relationship & over 5 yrs & Once $^{*}$ & Yes \\
\hline 4 Timothy & Male & over 70 & Widowed & over 5 yrs & Multiple"* & No \\
\hline 5 Graeme & Male & $61-70$ & Married & over 5 yrs & None & Yes \\
\hline 6 Steven & Male & $61-70$ & Relationship & over 5 yrs & Multiple"* & Yes \\
\hline 7 Mark & Male & $61-70$ & Married & under $6 \mathrm{mths}$ & None & No \\
\hline 8 Jamie & Male & over 70 & Married & over 5 yrs & Once & No \\
\hline 9 Luke & Male & over 70 & Married & $1-4$ yrs & None & Yes \\
\hline 10 John & Male & $61-70$ & Divorced & $1-4$ yrs & Once & No \\
\hline 11 Cathy & Female & $41-60$ & Married & over 5 yrs & Once & Yes \\
\hline 12 Maggie & Female & under 40 & Single & under 6 mths & None & No \\
\hline 13 Michael & Male & $61-70$ & Married & over $5 \mathrm{yrs}$ & None & Yes \\
\hline 14 Neil & Male & over 70 & Divorced & over 5 yrs & Multiple & No \\
\hline 15 Shawn & Male & under 40 & Relationship & over 5 yrs & Multiple" & No \\
\hline 16 Norman & Male & $61-70$ & Married & over 5 yrs & None & Yes \\
\hline 17 Ramsay & Male & $61-70$ & Married & over 5 yrs & None & Yes \\
\hline 18 Jason & Male & $61-70$ & Married & over 5 yrs & None & Yes \\
\hline 19 Stella & Female & $61-70$ & Married & under $6 \mathrm{mths}$ & None & No \\
\hline 20 Stewart & Male & $61-70$ & Married & over $5 \mathrm{yrs}$ & None ${ }^{* * * *}$ & No \\
\hline 21 Thomas & Male & $41-60$ & Married & $1-4$ yrs & None & No \\
\hline
\end{tabular}

*Said to be inappropriate

$*$ Consecutively known as a 'storm'

$* * *$ it was not clear whether Stewart had received shocks or cardioversion or indeed, both 
the everyday cyborg. That is, there were cases where the everyday cyborg had experienced a shock, but the ICD had not recorded it (a 'phantom shock') or occasions when the ICD had fired, but the everyday cyborg had not been aware of it.

\section{The broken hearts}

Most had had a specific event or incident relating to their heart. However, others, as I said above, had had the ICD fitted for the prevention of an SCA despite not having experienced any type of cardiac episode (Maggie and Timothy). Attempting to assess whether different experiences relating to the ICD had some association with the kind of cardiac event (failure, disease, attack, arrest or genetic probability of having an SCA) or not is challenging to tease out in such a small sample. Two individuals, Maggie and Timothy, appear to have had more problems than others in living their life with their heart device, for example, alienation at implantation and device activation. Maggie had not experienced an SCA, and Timothy had no recollection of having had one. Without warning, and while visiting a friend in the hospital, Timothy had lost consciousness, and the next thing he remembers was waking up with the ICD implanted. Maggie has the genetic condition ARVC which led to her having an ICD implanted prophylactically. At 32 years old, she was the youngest of the group and was also the 'newest' everyday cyborg having been recently implanted only six weeks earlier. She was a keen runner and had been training to run half marathons but this was no longer possible for her.

\section{Heart attacks and SCAs}

Although he had suffered his heart attack 20 years ago, Steven could vividly remember the circumstances of it. He recalled that he was having his hair cut when he felt a pain in his chest, accompanied by feelings of intense nausea and sweating. He managed to make his way home where he felt the pain then becoming unbearable, comparing it to an 'elephant standing on his chest'. He called an ambulance and had three consecutive heart attacks in the hospital. These 
heart attacks had caused the structural damage to Steven's heart that would, over the years, affect the heart's electrical impulses required for a steady-state heart rate, leading him to have an ICD implanted.

Mark was in his late 60s when I interviewed him and had worked as a servitor at a university. He reported how, over many years, his heart failure had gotten progressively worse, and indeed his heart was slowly failing him, and there was no cure. Mark told me: 'It was getting worse and worse with the breathing that I was putting my socks and pants and that on by numbers, $1,2,3$ go ...' The ICD he had implanted had pacing abilities as well as a defibrillator and he believed the pacing element helped his breathing.

Eleven of the everyday cyborgs I interviewed had survived an SCA. Cathy was 43 years old, and a police officer when I met with her and her husband. She had previously been diagnosed with LongQT syndrome, however, her arrhythmias she believed were being well controlled with the use of beta-blockers. Then she recalled 'blacking out' at work during a physical training exercise:

Cathy: Luckily, there was a PC who was a nurse in her former life was there, and they were about to perform CPR on me because I'd gone blue when I came to. I remember hearing voices, but everything still being dark at that point, and it was almost like I was frightened to open my eyes to see what was going on, but I couldn't. Again, it could probably only have been a matter of seconds, but for me, it felt a while.

Cathy was one of only a few everyday cyborgs able to return to work, albeit on desk duties after her ICD was implanted. Happily, Cathy and her husband became parents to twin daughters, and the ICD had little effect on the pregnancy.

Five years previously, Ramsay suffered an SCA at his motherin-law's funeral. Previously he had been in robust health with no health conditions or indications of any heart problems. He would not have survived the SCA if it wasn't for his wife's sister, who was a nurse, administering CPR. Ramsay remembered little of the incident. He has changed since, however, as his wife Fay recalled during our interview:

Fay: He's not the same person as what he was before he had that. Gill: In what way, do you think? 
Fay: His mood swings. His temperament now, he's, he is not the same person.

Later, when Ramsay had left the room, she added:

Fay: He [Ramsay] never used to like being left on his own, like, well, him, he wouldn't be able to watch Aidan [grand-son] to start with either, on his own [after ICD implantation]. Whereas before it, it [SCA] happened, he used to watch him. But no, he's a bit anxious now. If, if he's left for too long, I think, on his own.

Previous studies have discussed the anger, anxiety and depression that can result from either a heart condition or living with an ICD. However, it was unclear which had had the most significant effect. Ramsay suggests it was to do with losing his job:

Ramsay: Aye. I think it's just frustration of not being working, honestly.

Gill: Do you?

Ramsay: I think so; honestly, I think that's what it is.

Gill: Right. So it's not anything to do with, it's not anything to do with the, the cardiac arrest ...

Ramsay: I don't think so.

Gill: ... or having the defibrillator, or anything like that?

Ramsay: No, no, honestly that doesnae bother me, eh.

For Ramsay, the source of his frustration was based on his inability to return to his work in the building trade which gave him a sense of purpose as a 'bread-winner,' and he appeared to have had a strong male circle of friends and acquaintances. His tentative answer ('I don't think so') that it was not the SCA that had changed his identity suggests there was more to the effects of the SCA than Ramsay would admit in the presence of his wife. Ramsay, like other everyday cyborgs in this study (and in studies with cardiac patients discussed in the last chapter), can, as Charmaz has described: 'Chronic illness assaults the body and threatens the integrity of self" (1995: 657). Further, 'ill people adapt when they try to accommodate and flow with the experience of illness' (1995: 67). Ramsay may still be adjusting; his wife Fay suggested that 'he wouldn't be able to watch Aidan to start with', implying that he could do so now. 


\section{Outside-in: cyborgisation will be televised}

The creation of an everyday cyborg is a relatively fast and visually unique experience in which the patient is conscious and aware throughout the procedure. A local anaesthetic is used as it is beneficial, 'in terms of procedural cost, duration and safety in patients' (Lipscomb, Linker and Fitzpatrick, 1998: 255). The procedure to insert the ICD system takes a matter of hours in an operating theatre (OT). The cardiac surgeon, supported by a team makes a $5 \mathrm{~cm}$ opening in the left-hand side of the chest (akin to where the top pocket of a jacket might sit). The ICD wires are manoeuvred from the chest incision, into the atrium of the heart and the ventricle, before the generator is placed into the pectoral chest. A representative of the ICD manufacturer is present during the procedure to advise on the use of the hardware, for example, the thickness of wires. Guiding the wires into the chambers of the heart requires the cardiologist to have significant levels of skill and patience attempting to do this when the heart is beating. Indeed, as reported in the last chapter, ICD manufacturer Medtronic voluntarily recalled their devices that had thinner 'sprint fidelis' leads as making the wires thinner to aid the process of implantation entering into the heart was predicted to lead to potentially higher mortality rates (Ellenbogen, Wood and Swerdlow, 2008).

The soon-to-be everyday cyborgs have their faces partially covered so that they cannot see what the surgeon is doing to their body, but they can observe the progress above their head on two monitors. As Mark wryly commented when recalling details of the procedure, 'I never knew it was all done on the telly.' For some the visualisation was enriching, as Alfred related:

Alfred: So, to, that was a positive and as I say, I found the actual
receiving it quite an interesting exercise, because you're really quite
awake, apart from the local injection on your chest and your throat
because they would have to break into your vein to get into your
arm. You're watching all this on ... and, watch them screw the wire
into your heart.

Different reflective surfaces and mirrors in the OT also offered an alternative visual experience to some of the patients during the procedure: 
Maggie: ... well, I suppose it's a light, it must be one of these big lights that you can pull down, but it's, like, mirrored, it's, like, reflective. And I could ... so I could see. So, I saw them making the incision, and I could see, um, like, my muscle, and I could see, like, a little bit of fat. And I was saying, 'is that fat?', 'is that fat?', 'why is there fat there?' [Laugh]

Glimpses of the inside of their body was a unique and fascinating experience for a few. The visual experience of watching the wires being carefully threaded and pushed into the everyday cyborg's body is simultaneously experienced on the monitors while occurring in their bodies; they can see into the muscle and as Maggie asks 'is that fat?'

Other everyday cyborgs found the insertion uncomfortable. Stella, despite being heavily sedated, recalled that the procedure had painful moments. She remembered telling the cardiologist: 'I can feel you cutting me ... like something stinging' and that how 'at that point they [operating theatre staff] just pumped, pumped more in, the sedative or something, whatever they give you'. This incision can constitute a painful breach as the first stage of the implantation for the patient as feeding the wires into the heart is a challenge for the surgeon.

One of the last phases is placing the battery and the generator into the cavity of the chest. Internally, the body is tightly packed with organs, and there is little extra room for adding an ICD despite it being roughly the size of a matchbox. Both Ian and Michael remarked on how painful this aspect of the procedure was for them:

Ian: ... as if I was going to go right through the trolley. I mean he apologised again like for pressing so hard, it was to get this. I couldn't visualise as to what it even looked like. I was very surprised when ... I mean it's just a, it's just a box.

Ian's wife: And it says a lot for them [surgical team] too because they're ... I mean, they're human beings. I know it's their job, but it must affect them but they must be able to shut off after they've done their job, but they must ... I mean, they know they're inflicting pain on you but it's for your own good, you know.

Ian seemed surprised about the actual size of the ICD - 'it's just a box' - which appears to indicate that, based on his experience 
of the device's implantation, the ICD felt more substantial than it was. Ian's wife was quite philosophical about Ian's experience, commenting on the ability of those present in the OT to disassociate in order to continue with the procedure. Michael found his first ICD implantation very painful:

Michael: It's all over with me, I've been through so much pain in my life it doesn't really matter. I don't know why it was so painful, but they seemed to keep pushing and pushing into my shoulder blade. I said, 'no, I can't put up with much more of this'. 'I'll give you some more relief', he said. I don't know what they did, but they gave me some more relief, but that didn't work, then all of a sudden this guy kept pressing, and I just passed out from the pain. I couldn't put up with it, it was horrible, one of my worst experiences. But then when I saw that this thing, it was like a matchbox, that's why I suppose they're [ICDs] flat now.

Michael was understandably anxious when he had to have his ICD replaced due to the depletion of its battery. His concerns proved to be misplaced as the second time Michael said he was in 'fairyland' and did not recall any discomfort whatsoever. Indeed, a study conducted in 1998 reviewed 33 patients' experiences after having an ICD implanted using local anaesthetic and sedation, and found that almost none recalled the procedure, although one reported awareness of 'pushing'. Seven suggested the process was painless but recalled a test shock reporting either awareness or discomfort with the shock (Lipscomb, Linker and Fitzpatrick, 1998). None of the everyday cyborgs in this study reported experiencing a test shock - when the ICD is implanted the shock discharge can be tested to ensure the ICD will work at the heart rate threshold that has been set for the individual.

Although patients like Stella mentioned above, found the incision the most painful assault on the skin, others reported that the surgeon's attempts to find a space for the ICD in the chest was extremely uncomfortable. The placing of the ICD generator into the chest cavity requires the surgeon to use some force and can be a difficult experience for both the surgeon and the everyday cyborg. There is little space inside most human organs, apart from the lungs, stomach and inner ear canals. Unlike organ transplantation where the organ is often removed (exceptions being in the case of kidney transplantation), anything that is added to an already full viscera space will protrude. As a result, the ICD causes a bulging 
from under the skin and is a permanent silhouette on the skin of the chest. A few participants reported that the outline could be troubling for them, and Timothy admitted to having never really got used to having the ICD in his body. He related how 'your body shouldn't have a square lump like that'. The placing of the ICD leaves a scar and an imprint, a silhouette on the skin, marking where the intrusion occurred and where the body's integrity has been breached. The ICD is very noticeable in the few weeks after surgery and at times after that, where the skin silhouette acts as a continual reminder of the presence of a cybernetic system. In Leder's terms, the ICD is causing the body to become an 'absent absence' (1990) as shown in John's comments:

John: And it's almost like ... and I don't want, I don't want to be ... it's a bit like being continually reminded that you've got this condition. I mean, in some respects I would rather just blend into society and just become an ordinary person again, you know.

Gill: Do you not think you're an ordinary person?

John: Well, I feel I'm, to some extent I feel extraordinary because I feel ...

Gill: Extraordinary. [Laughing]

John: ... I'm being kept, I'm being kept alive by that, you know.

The silhouette of cybernetic technology is a reminder of the everyday cyborg's mortality. The daily routine 'absence' of the body was no longer absent; the body and especially the scarification and silhouette caused by the ICD on the chest resulted in a heightened awareness of it causing what Leder (1990) calls a 'dys-appearance'. Notably, there is no subjectivity alteration said to occur at this point as is the case of organic human or non-human animal transplants.

\section{Inside out: an absent absence}

The rehabilitation for most everyday cyborgs did not have adverse or damaging consequences. This is not to say that it was not challenging and frequently mentioned was the on-going unwelcome presence of the ICD in the body. It is a tangible sensation both through sight and touch, but its presence constitutes more than sensory perception. In regular interaction, Leder suggests different 
regions of the body 'recede' from direct experience and therefore constitute an absence (1990). Our absent bodies are a daily aspect of everyday living, and it is only at times of bodily change or pain that our body becomes present. Such body modification, as in the case of ICD implantation, causes the 'absent absence' and a 'dys-appearance' (Leder, 1990), meaning that absent bodies are no longer absent.

For some, the feeling of the ICDs causing an 'absent absence' inside their body was particularly acute in the weeks that followed the surgery. From inside the body, the feeling of the ICD's presence was there variously when showering, lying down or sleeping on the left side where the ICD was placed. This meant that initially at least, the everyday cyborg had to alter their posture and their body's usual resting position. Audrey said: 'I can't sleep on that side [where the ICD is], I have to sleep on my back or on my other side.' Stella suggested a similar experience: 'I can feel it, sometimes, if I'm lying down, it'll jut out a bit more and I'll go ... (makes a movement to push it back).' Alfred suggested:

Well, I'm really quite thankful because I mean it's saved my life bloody three times. But, it is a bit of an inconvenience, because it does stick up and, you know, you can, when you're sleeping, it kind of interferes if you're on one side.

The ICD is a foreign device and to some constitutes an alien invasion creating an absent absence in that part of the body. For Jason, he related to me how: 'I felt that you ... you were conscious of it being there all the time'. The newest and youngest of the everyday cyborgs, Maggie, who had her ICD implanted six weeks previous to our interview, was initially concerned about how her everyday movements might affect the positioning of the ICD:

I wasn't moving my arm really, but yeah, I was ... er, the first initially ... yeah, yeah, I was really worried about, um, you know, lifting things up and the wires dislodging. Which I now understand is actually really pretty difficult.

In a conversation we were having about her sister's pregnancy, Maggie drew out the differences between them:

Maggie: ... you know, whatever. Um and again, you know, they can help the ... turn the baby around and get the baby out and what 
not. But it ... like, to put a machine, um, something that's not natural to keep you alive, I'm not sure that I'm totally 100 per cent convinced, even though I've got one. [Laugh] You know, and since I got it implanted, I've thought about it even more.

Maggie had difficulties accepting the ICD because, to her, it was a machine and was therefore 'unnatural'. Her statement that 'I thought about it [ICD] even more' demonstrates how an 'absent absence' of the ICD is a presence in the lives of everyday cyborgs. The daily routine 'absence' of the body was no longer absent; the body, and especially the scarification and silhouette caused by the ICD on the chest, resulted in a heightened awareness of it. Jason discussed how difficult an 'absent absence' is and the feelings that resulted:

Jason: ... once that got fitted in there, I wanted to tear it back out again. I did ... I was quite ... I ... I don't know what the word was, but I just didn't like it in there ...

Gill: No.

Jason: I didn't want it.

Cyborgisation incurs emotional costs and creates disturbing thoughts. Although Jason eventually acclimatised to his ICD, he reported initially being "more thingmied (scots slang for "agitated" or "flustered") about the ICD as I was about the blooming triple bypass operation, believe it or not.' When probed on why this was the case, he suggested, 'Just the thought of it [ICD] being there. Aye, that's all it was.' Hence, although I have emphasised the importance of placing the everyday cyborg's voice and vernacular at the centre of the story about the cyborgisation process, there are, for some, no words that can describe the various thoughts and feelings it causes. There is no vocabulary or lexicon readily available to describe this condition of neither being sick nor well - that is, not a disease or illness - but neither are they in an altogether healthy state, so perhaps better described as an 'un-health'.

\section{See me; feel me}

Most everyday cyborgs were discharged from the hospital within a day or two although recovery could take much longer. This has 
implications for the economic independence that breadwinners such as Ramsay, above, mentions as finding frustrating. The consequence for some could be particularly harsh. Thomas, like Ramsay, worked in the trades. He was a plumber until he lost his job:

Thomas: Mm. I ... I was ... well, I do feel I was a bit ... I don't know if it's anxiety or depression or anything, but after I got it done because I was off my work ...

Gill: When, er, the device got fitted?

Thomas: Aye and then, I ... they said about six weeks [was needed for recovery], and then I used all my savings to keep the house going and then ... So I ... I ... I claimed house insurance and they said, you never declared you had a heart condition. I said, look at my last mortgage ... my last mortgage, but, er, I lost ... well, I ended up ... had to go bankrupt. I lost my house. Everything.

'He lost everything'. Thomas lost his job as a trade plumber and his house, leading him to file for bankruptcy. Thankfully such consequences were infrequently reported during interviews, although the loss of employment was a common theme in all of them. It is difficult to tell whether the loss of employment has to do with the physical limitations or the restrictions on driving that follows the ICD implantation. For some, however, it was clear that their lives were irreversibly altered and they needed to adjust. To accomplish this adjustment and acclimatisation, they employed strategies to balance what they had lost, against what they had gained (as discussed below).

\section{Acclimatisation and sinking}

The ICD constitutes, for most everyday cyborgs, a presence, an irony when absence that is absent, or in Leder's terms, a 'dys-appearance' (Leder, 1990). Sobchack (2010) writes of how this dys-appearance plays out in terms of amputation and of prosthetics. She expands on Leder's dys-appearance by noting that 'what is physically absent and what is ostensibly artificial can be - and often are - more experientially present or embodied than birthed, intact, or residual limbs' 
(Sobchack, 2010). The ICD device breaches the body integrity and image and is more present; it is straddling the body boundaries of inside-out and outside-in and through its placement, causing the absence of that particular body site to become present. Just as it can be even more present, then so it can be less present in experiential terms. It is a process that is fluid and subject to change over time. It is the case, as Dalibert observes in her research with patients who have a deep brain stimulator, that the device is 'under the skin [and] amounts neither to ... disappearance nor to its transparency but rather entails new body-technology configurations and ways of being in the world' (2016: 216).

For some, the 'absent absence' issue was never an issue to begin with. Stewart suggested that, although he was conscious of his ICD catching on clothing, it did not concern him. Jokingly, he remarked: 'Luckily I don't wear a bra [laughter].' Three of the four everyday cyborgs were women, and there was some mention of concern about body image, but for Stella: 'No. You wouldn't know it was there until, I mean, unless you saw this wee bit sticking out.' Both Stewart and Stella did not report any concerns at all about their ICD and felt the benefit from it - as I shall cover later, their ICD journeys were not beset with some of the challenges that others had. Although an ICD would settle into the body, overcoming dysappearance took variable amounts of time and different strategies.

\section{From alien invasion to part-of-me}

The new 'body-technology' configuration that Dalibert (2016) refers to can involve a level of incorporation (De Preester and Tsakiris, 2009) or acclimatisation (Haddow, Harmon and Gilman, 2015). In the case of the ICD, the dys-appearance is resolved through a process of acclimatisation. This involves the ICD becoming a part of the body, and no longer an alien presence. For example, researchers argue that prosthetic users are encouraged to view their prosthesis as a 'corporeal structure' that is more than a tool like a cane or walking stick (Murray, 2004). De Preester and Tsakiris draw upon an account given by a man who was born without a foot (quoted in Murray, 2004): 
One of the major factors in my satisfaction with a new prosthesis is how little I feel it. That may sound strange, but to me, my prosthesis is an extension of my body. (I can actually 'feel' some things that come into contact with it, without having to see them ... It must 'feel' as close to not being there as possible.)

(Murray, 2004: 970 quoted in De Preester and Tsakiris, 2009: 310)

Like the interviewee in Murray's study, when I talked with Maggie roughly ten months after our first interview, she described how her relation to her ICD had changed from its initial alienating presence:

Maggie: There's ... yeah, 'cause as in, basically, if I was to try ... if you think about it in the opposite sense, if something happens to my body, the wires ... you know, the wires do something. And it is, it's part. So, of course, maybe in, like, fifteen years or ten years' time, I will actually feel, you know, this is ... it is part of me. And I suppose, in a way, maybe, you know, you might accept that it's ... it's strange to think of accepting a piece of machinery that, sort of, is ...

(emphasis added)

Moreover, Neil drew an interesting analogy between his body and that of a ship:

Neil: ... was that when the device first goes in, it's, kind of like, a, kind of ... it's more of a foreign body, if you like, to your ... your system ... and then once it had been in a long time, it, kind of ... the wires and everything else that's there, kind of, get covered in all the, sort of, gunk that goes round your body and it becomes less and less of a, kind of, foreign body over time, because it ... you know ... you know, I suppose like a ship in the sea, it gets covered ... you know, like ...

Gill: Barnacles?

Neil: ... it gets covered in barnacles and all these type things ...

Neil suggests that the ICD undergoes a physical transformation as it gradually becomes coated in the 'gunk' of the organic body and therefore becomes less 'foreign'. Audrey described the ICD as 'being absorbed' into her body. John discusses how his ICD became physically less prominent:

John: I mean, I mean I was obviously aware of it [ICD] being there. 
Gill: Were you, uh-huh?

John: And in fact, I think I've put another half an, half an inch of fat over here since then.

Gill: [Laughing]

John: But when I got it, it seemed actually more prominent than it is just now.

Over time the ICD and its silhouette on the body becomes an absence again that characterises much of the relationship we have with our body in everyday life. We manage to not pay attention to the status of our bodies or indeed, our relationship with them and therefore are able to get on with our day-to-day living. What is perhaps remarkable is that for most, the ICD quickly and easily becomes part of the body and more significantly, part of the person. Stella had received a specialised ICD called a CRT-D to treat her heart failure, a device that is implanted with an additional wire around the back of the heart to coordinate a more efficient heartbeat. She told me that she 'instantly felt the benefit from it, if I didn't have it [ICD], I wouldn't be able to breathe, you know'. She readily suggested, 'it's just part of me now, it's no big deal'. For Stella, her ICD allowed her to breathe and gave her her previous life back. Stewart reported that his ICD was, 'You know. It's like my shoes. You know, I don't consider my shoes alien. I don't, I mean it's, obviously I wasn't born with it, but it lets me be who I am' (emphasis added). The turning point for Jason coming to accept his ICD was when the life-saving benefit of the ICD was explained:

Jason: I did, aye. I wanted it out ... I told ... I asked them [medical professionals] that when I went up. And I got a bollocking, of course. [Laugh] And of course, the ... the nurse ... the ... the ... the lady said to me, she said right away, she says, well, $\mathrm{Mr}$ Campbell, she says, I'll tell you the truth, somebody had theirs in there for about years, just the same as you and they says ... but ... what the ... if ... if they didn't have had it in there, but a couple of month after it, er, the thing took a ... a ... a ... a ... it fired ...

Jason's wife: Uhm-hmm.

Jason: ... and saved the bloke's life ...

Gill: Right. Uhm-hmm. 
Jason: ... and of course, ever since then, I've really said to myself, well, it's there for a reason really ... So I've been a wee bit more ... knowing ... I wasn't going to say happier, but I'm a wee bit more relaxed to the situation now and ...

Jason's wife: Uhm-hmm. Time heals, doesn't it?

The acclimatisation to new hybridity for Jason was a process initially hindered by not experiencing the benefits of the cyborg life. However, time does heal, as Jason's wife remarked, in terms of a new comfortable synergy between the ICD (cyb) and the body (org).

For others, like David, if time was not a healer, then therapy certainly was. David was one of the oldest everyday cyborgs, and he had been fitted with his ICD 20 years previously. His accounts of his early experiences are similar to those that were shared by Jason. David related how it had stopped him 'sleeping, it was making me anxious ... it just had changed my body a bit and, I ... I felt it wasn't part of me in that it was a machine'. He offered a retrospective view of the way his relationship to the ICD changed over the years:

David: ... when I first had this implanted, I, you know, it felt very much like my enemy, despite the fact that it could potentially save my life. Um and by the end of this long journey, I feel that ... I would feel very strange, without it, you know ... and so, um, I feel it has ... it has really become part of me in a way that I didn't ever expect it would.

(emphasis added)

It was not until he had sought therapy that his relationship to the ICD had changed. Indeed, current guidance by the National Institute of Clinical Excellence in the UK has suggested that approximately 5 per cent of patients with an ICD need cognitive behavioural therapy after implantation (NICE, 2014: 40-41). However, this appears only to be a recommendation and is not widely available in the UK despite the variability in the way that acclimatisation to the alienation reported since implantation is resolved. For the everyday cyborgs, Maggie, Jason, David and Timothy, who reported issues with the ICD causing a bodily absent absence, they did not necessarily experience the benefit of the device. On the contrary, it could signify the life they had previously but had no longer. Then the process of acclimatisation and the ICD can be facilitated when the 
benefits of the ICD is experienced; it becomes a comfortable part of the body and a 'part of me'.

\section{Others: protecting the ICD from others}

Despite the ICD transformation from alien presence to a part of the body and 'part of me', it still required protection from the unexpected physical movements of other people. The everyday cyborgs seek to protect the ICD hardware from accidental damage by others. The unpredictability of other people's movements became important because the ICD is sitting inside the body but not far enough in as it was still noticeable from the outside. Then although it was far enough inside to be out of reach of the everyday cyborg, this did not mean that it felt safe and secure against blows or accidental damage from others. Perhaps partly due to its position as not being fully inside the body, it was thought to be at risk from others that could inadvertently damage the device:

Luke's wife: My great-granddaughter will be eight this year and she comes up and torments him, he'll say go away because he's scared she would knock it.

Gill: [turning to Luke] Do you think she would ...?

Luke: I don't know if it would do any harm but I'm not taking the chance because she's so coarse ('heavy handed') the way she flings herself about.

The everyday cyborg's avoidance of physical contact was specific to the situation. It led to them avoiding certain individuals and environments that were deemed potentially damaging to the ICD, and perhaps by the association to the everyday cyborg. Jason was unable to visit the garage where he was previously employed due to some of the specific environmental restrictions such as avoiding arc welding, as well as being careful to avoid the physical demonstrativeness of his workmates:

Jason: ... and when I went to my work, drivers were periodically ... or mechanics, they were putting their hands on the back of my shoulder like that and gripping me and they were 
forgetting that I had ... And there was a lot of things like that and the garage itself ...

Jason's wife: Right in there, was about all his, sort of ...

Jason: ... had a lot of mechanical parts in there and it was all magnets and God knows what it was in there ... and I was dead scared to go in there in case the thing was going to set off and ...

Jason's wife: [Laugh]

Jason: ... it was terrible.

In terms of clinical guidance, everyday cyborgs are advised to avoid contact sports such as rugby, avoid magnets, airport and security devices, diathermy, MRI scanning and, in Jason's case, arc welding.

\section{Check-ups: by significant others}

The everyday cyborg might mostly be male, but he was not a 'Robocop' or even like the android 'Terminator'. On the contrary, he had the potential to suffer a cardiac event, and this resulted in over-protectiveness by the everyday cyborg's wife (or husband). Some like Ramsey and Jason clearly articulated how their masculine role as bread-winner had altered, for example. This led to tension in their close relationships. Fay, Ramsay's wife, recognises Ramsay might construe some of her behaviour as being 'overprotective' but she defended this by saying:

Fay: Because he cracks up with me, Gill, because anywhere he goes, or when I'm away to my work or that, I'll phone him umpteen times a day. And he cracks up with me ... for god's sake, for god's sake! And I'll say, you werenae there that day, you didnae see what happened, ken.

She was witness to his SCA at her mother's funeral, and it was only due to her sister's intervention that Ramsay's life was saved. Then although her behaviour was viewed as being 'over-protective' and was complained about, it was entirely justified in Fay's view because she witnessed just how close Ramsay came to dying that day. The ICD was to protect the everyday cyborg from SCA; however, significant others saw their role now of protecting the everyday cyborg from themselves: 
Mark's wife (on my second visit): It's a wee bit easier now, but at the start he wanted to go out and do things and he (Mark) just wasn't ... I mean I was terrified he would fall. I mean I only go to the wee shop and back again because I'm terrified in case he falls again. It's caused so much agro between us because he wants to do it and I'm saying to him, don't do it. Or will you please stay there till I come back? But, I mean, I get out on a Saturday, John [their son] takes him away a run [in the car] for the day.

Mark's wife: That's and then ... but of course one of the family came and sat with Mark until I came back.

Mark: Babysitting.

Understandably, for significant others, the implantation of an ICD was viewed with a tremendous sense of relief and gratitude. The ICD is intended to prevent an SCA occurring and indeed is so efficient that it will continue to shock the cyborg even when it is unnecessary to do so (as discussed further below regarding the circumstances of removal). The ICD can, therefore, be an additional layer of protection, watching along with those closest to the everyday cyborg. In some cases, it could allow them to step down from certain aspects of surveillance:

Stewart's wife: ... when he (husband Stewart) was very ill I was concerned because you'd go to bed at night, this was before he had his ICD put in, we'd go to bed at night, and I'm listening to his breathing because sometimes ... it sounded as though he was going to stop. And then I thought, 'oh God, something's going on' and then he would breathe again. So, I really was, he was totally unaware of that because he was asleep ... So that I was very keen for him to have an ICD because I thought, well at least if I'm asleep and he stops breathing or whatever then something's going to happen to, to save him.

Loved ones and significant others were fully aware of the ICD's benefits and saw it as life insurance. In an exchange between Audrey and her husband Joseph, Audrey's ICD was explicitly referred to as 'life insurance':

Audrey: Yes, I just ...

Joseph: It's like having an insurance policy ...

Audrey: ... take it for granted. 
Joseph: ... you hope you never use it, but it ...

Audrey: Yes.

Joseph: ... it's good to know it's there.

Audrey was in her 80s when she received her ICD, and she believes that protests made by her daughters led to an overcoming of the initial reluctance to give her one. This may or may not be a reflection of the 'cyborg sexism' I discussed earlier when fewer women than men receive an ICD despite their propensity to suffer similar rates of heard conditions, albeit at an older age. The ICD is quite literally a form of life insurance and provides reassurance to significant others that they will not lose their loved one from an SCA. It does not mean that the significant others can stand down from their surveillance over their loved ones, however. Their loved ones still keep watch over the everyday cyborg to ensure they are not causing themselves any harm by what they see as potentially harmful behaviour, for example, by climbing ladders, which rather curiously was mentioned in several interviews.

\section{Putting the ICD through its paces}

For significant others, the ICD is 'on watch' from inside the bodies of everyday cyborgs, offering protection from an SCA through its C3I. The ICD can maintain close surveillance even when significant others are absent. However, the ICD itself requires check-ups, and hence the everyday cyborg is required to attend 'pacing clinics' for the device to be reviewed regarding battery depletion, evidence of cardioversion incidents or discharge of shocks:

Alfred: So, this type, I suppose it can pace your heart, speed it up or slow it down, but it can also cardiovert ...

Gill: Have you felt it pace? Have you felt it ever pace?

Alfred: I have had it happen to me in the clinic, because they speed it up and slow it down.

Gill: What does that feel like?

Alfred: It feels really odd, I have never really been aware of my heart very much, although some people are. So, having it speed up or slow down, you're very conscious as to ... but, you know, there's no reason for it to be done, it's not like 
you've been running or something, so it's very strange, well, to me strange.

Stella echoed the odd sensation of her heart rate being slowed:

Stella: They only put the wires on your legs, and where they usually put it, on the heart. But then they take your monitor thing, and they put it there. But then, they do all the things through the computer. And so she'll [electrophysiologist] say, 'I'm just gonna slow the heart'.

Gill: She told you that?

Stella: Aye.

Gill: Uh-huh.

Stella: And I think she done that a couple of times. But one of the times, I felt really woozy with it, and I was saying, oh I didn't feel right. And she just said, oh I'm sorry. And then, they did, you know, they click on the heart, and it just makes you feel all funny for a wee few seconds.

\section{Remote monitoring}

The ICD's surveillance functionality can be extended by exploiting the communication part of the C3I function for remote monitoring. Clinicians had given a couple of the everyday cyborgs in this research remote monitoring devices. These devices replace most of the clinic visits that the everyday cyborg undertakes every six months or so for a check-up (more frequently if the battery levels were depleting or if the device had fired). The upload of activity remotely from the ICD is scheduled with a date and time in advance, or as Stewart paraphrased it, he received a letter requesting him to 'plug yourself in'. Stella asked for a remote monitor when she was at the hospital clinic and was given one right away. 'It plugs in at the side of the bed. Lift it up, place it over the device, and it downloads everything,' said Stella. There are growing fears as discussed in the last chapter that hackers would be able to either interfere with the functioning of the device or capture data from it. When I asked Stella about the possibility of hackers using her data or accessing her device, she questioned the motivation of malicious intention, asking 'why someone would expend time, resources or energy in hacking 
her medical device?' As only a few of the everyday cyborgs had a remote monitoring unit, it is difficult to ascertain how common Stella's view was.

Generally, the remote unit is kept beside the bed. I asked Stewart if he knew why this was the case:

Gill: I'm trying to think, why wouldn't they have it near you while, while, they wouldn't have something like during the day time that they would pick up an event, you know. Why is it like you say ...?

Stewart: Because I'd be conscious then and I would know what was happening.

Gill: So, at night?

Stewart: Often, often my ... often my arrhythmias are, are at night. They're momentary, I mean they'll say, oh it only lasted, you know, nine-tenths of a second or something. But it's often and often just before you waken up in the morning.

While the cyborg sleeps, the sensory and communicative system of the ICD does not. What caused some concern from Stewart, however, as he humorously related, was that the medical profession could 'spy' on the everyday cyborg:

Stewart: And she [electrophysiologist] said, she said, 'well your pacemaker ${ }^{1}$ paced you and it didn't work and your pacemaker paced you again and it didn't work. And it charged up and it was just going to zap you and your heart sorted itself out.' [Laughs] But I found it's quite scary that she [electrophysiologist] can spy on me like that. [Laughs]

Essentially, the ICD can offer further surveillance for the medical experts into the patient's body even when the patient is not present in the clinic or even awake. This surveillance by clinicians is one whereby they can tell when the everyday cyborg is awake and active or at rest due to the activity level of the ICD. Unlike ten of the everyday cyborgs, Stewart had not received a shock and had an unproblematic relationship with his ICD. However, five of these ten had received shocks multiple times on the same occasion - an event known as a 'storm'. It is the narratives about shocks that I turn to next. 


\section{Reconciliation: shocking moments}

Medical devices, such as ICDs, I have argued, can be considered cybernetic; defined as having a smart functionality fulfilling Haraway's C3I features, of command-control-communicationintelligence (1991). The cybernetic functionality takes the form of a feedback loop that senses a change in the environment, in this case, the heart's beat, and establishes an intervention to reinstate normality (through a series of small electric shocks to cardiovert) before assessing the success of it and possibly scaling up to shock the everyday cyborgs. The ICD can administer shocks up to 40 joules, which is much lower than an external defibrillator can (100$360 j$ ) but can still be painful for some. ${ }^{2}$ Sometimes the shock can be given at least half a dozen times or more, before then recording and communicating the events either through remote monitoring or interrogation of the device at the clinic afterwards. For the everyday cyborg, a life-saving shock is an event that is not inevitable but is always possible. This possibility of shock may form a core part of the love/hate relationship the everyday cyborg had with their ICD.

Alfred's ICD had been implanted 11 years previously, and he experienced shocks on three separate occasions. Alfred's wife, Jean, said that when the ICD shocked Alfred the first time, she thought he was dying:

Jean: Alfred just as he described, you were just sitting there, and Alfred actually had a drink in his hand and that's what I noticed first, I just saw liquid splashing and I turned round, and at that point trying to think, well his eyes were rolling back in his head, and I thought he was dying, I thought that was it, so I grabbed the phone to get the paramedics. Then he suddenly came to and jumped up, and I said 'sit down,' and I think at the point I was thinking it could have been something to do with that.

Gill: To do with the ICD or to do with his heart?

Jean: The ICD, uh-huh or heart, just something not right there, so it was a bit of a shock.

As she says, without any irony, 'it was a bit of a shock'. Alfred tended to see his multiple experiences of non-consecutive shocks, 
that is, shocks which had occurred on separate occasions, as not being entirely unexpected; he had had a general feeling of malaise or being 'lightheaded' before the ICD went off. Alfred had received a university degree in physics to which he linked his pragmatic attitude towards the ICD:

No, I think, I remember most of what happened, but I think I'm very pragmatic, you know, physics and stuff, so I tend to look at these things in a right factual sort of way, So, I knew I was in trouble, I knew they were wanting to give me something that would help it, so to me that was perfectly fine. The fact that I need to walk about with a thing inside me seemed to me the ideal position I was in, like if it was in your handbag and you left it at home sort of thing, you know, it's with you all the time. ... Anyway it all settled down so they let me go, and I guess at that point, you know, it's your first experience, and so it's doing what it says on the tin.

(Alfred, emphasis added)

The ICD is doing 'exactly what it says on the tin.'

\section{Pain and storms}

Two everyday cyborgs experienced storms or consecutive firings within one period of time. Steven reported how he had been hungover one day and this, he felt, had contributed to his ICD going off. Like Alfred, Steven had had some form of short-term awareness that his ICD was about to go off so like Albert, the shock did not come as a surprise, in that understanding of the word 'shock'. However, it had shocked him five times consecutively:

Steven's partner: And, he was lying here and I looked at him and $\ldots$ and he went, oh, here it's going again. And, h ... his body was just ...

Steven: Boom.

Steven's partner: ... jumping.

Gill: Lifting? Right off the couch?

Steven: Three times here, twice in the lift.

Steven's partner: And, he was chalk white ...?

Steven: But ... Aye, it's, er ...

Steven's partner: But, as he says, it saved his life. 
Understandably, Steven was keen to have the ICD removed after the ICD storm:

Steven: And, er, I says to him, 'doctor, get this out of me'. I says, 'I canny go through that again'.

Gill: Did you say that?

Steven: Aye, I said that to him. I say, 'you better take this out' ... And, he stood there, and he says, 'look, that device probably saved your life'.

His ICD discharges a shock on one other occasion which he explained: 'Well ... It went off once, but that was my own fault ... I was trying to lift something awfully heavy.' After that, and with adjustments made to his medication, Steven did not suffer any further firing. In contrast, to these painful episodes, two everyday cyborgs said they were hardly aware that their ICD had gone off. Stewart, for example, recalled:

Stewart: Having said that, when you are shocked, it's not the same result for everybody. As I said earlier, I get the [makes a small reaction] and it's like muscle jump.

Gill: Yeah, yeah.

Stewart: Some people have to be physically held on the bed. Erm, you talk to people who have been actually physically shocked when they're out and about. I mean like ...

Stewart's wife: When it's working.

Stewart: ... when it's working. And some people go from the bottom end of the scale really, really, you know, a bit unpleasant, to other guys [laughs] who says it's like being hit by a baseball bat. [Laughter]

Stewart was unaware of being shocked until his ICD underwent a routine check at the pacemaker clinic. He recalled: 'they actually have me down there which is what I went into three weeks ago and then that's when they suddenly turn around and said, "oh it's gone off".' Whether or not this was a full shock or a series of small cardioverting ones is difficult to assess. Interestingly the opposite event can occur when an individual reports their ICD has gone off, but this is not shown on the ICD records (as discussed in the last chapter). This is a recognised phenomenon known as 'phantom shocks' (Juan and Pollack, 2010). It is an incident that is more 
often likely to occur at night time, as was the case in Timothy's experience:

Timothy: A phantom shock, in my bed, then home in my bed I had two at least, only when I got to [hospital] I hadn't, it wasn't registered, but up here I had two hits. I thought. Whether I was sleeping and dreamt it I don't know, but I definitely had two shocks in my bed, phoned Anne again, she phoned the ambulance, the ambulance came and by this time I was ...

Gill: You still had the physical, the tremors and everything afterwards?

Timothy: Yes. But, when they read it, it registered nothing.

\section{Inappropriate firing}

So in some cases the ICD had fired and the everyday cyborg had not been aware of it, whereas in others, the everyday cyborg experienced the ICD firing when it had not apparently done so. Additionally, a couple of the everyday cyborgs reported receiving what they felt were inappropriate shocks. Inappropriate shocks were identified by two of the everyday cyborgs David and Shawn. Shawn shared how his first shock had been due to the wires being 'overly-sensitive'. This was related, he felt, to the threshold for the shocks being set by the electrophysiologist at implantation as too low:

David: I, you know, if I'm in a cinema, I want to see a film and, er, people, er, quite near just pissing about and talking a lot and if they're nearby you should go over and tell them to shut up, but they were quite far away, so I came out of the film with my friend, and I went up to them afterwards and started ... started an argument with them about making a noise in the cinema. And I was really, really angry and stressed out and as I, kind of, walked away, my device fired. And, you know, I can understand ... you know, I was really agitated and, you know, my heart was hammering ... but, um, I felt strongly that, um ... that one should be able to get into those situations in life and not worry that you're going to have an ... 
Gill: Yeah.

David: ... electric shot to the heart. So ... but the doctor said that my heart was extremely fast and dangerously fast and that's why ...

Gill: Uh-huh.

David: ... it fired. And they altered the settings a bit after that.

Gill: Did they?

David: Yeah.

Gill: As in the sense that the level of ...

David: They made the thresholds, um, higher, I guess, um, so that wouldn't happen again.

However, as I turn to next, shocks were less likely to be explained by device over-sensing but more likely to be explained by the activity of the everyday cyborg.

\section{Something else is in control}

Everyday cyborgs explained why the ICD had fired with nearly all linking the event to an activity they had undertaken. Excesses of worry, exercise, alcohol, coffee, excitement or feeling under the weather were identified as ways of explaining why the ICD had discharged a shock and therefore was inserting an element of control by the everyday cyborg. John suggested to me that his shocks were related to do-it-yourself exertions; Cathy suggested that over-exertion and 'something not quite right with the device contributed to her ICD firing'. Timothy had been shocked on two occasions: once in the excitement of a bowling match and on a later occasion when sitting on the couch. Timothy explained that the latter shock was due to his tendency to worry:

Timothy: I've said about I'm a worrier, so maybe that has got something to do with it ... Even now, that last time, beginning of last year, that was when I had one or two incidents ... there was worry then, there was a bit of panic then even when the incident happened, shaking and a right, they [clinicians] said a kind of panic attack, as well as something happening and that didn't help it any. I had to try and, Anne's [daughter] told me all this patter with deep breathing, it's easy to say but when this is happening to you. 
In some ways, 'blaming' lifestyles is the everyday cyborg's way of taking back control of their body. As David described how he was 'freaked' out when he first received his ICD: 'Well, I mean, it's the ... it's just ... I guess it's the whole ... it's the whole, this is all wrapped up, you know, feelings of control and feelings that something else has control of the core of you, I guess, you know.' As Jackson says, such strategies make us 'authors of meaning rather than victims of circumstance' (Jackson, 2002). In some ways, this finding can be interpreted as a means in which the everyday cyborg attempts to regain control. Or, at least, post-rationalise what had happened. In my informal discussions with cardiologists, they have suggested that within reason, there is little or no relationship between what could be termed the ordinary activity of the everyday cyborg and the ICD discharging shocks.

\section{Permanent removal, semi-removals and temporarily switching off}

The ICD can be switched off and deactivated while in the body through placing a magnet over the site of the ICD that will temporarily disable it from sensing and delivering any shocks. This magnetic device can be used to temporarily 'close the eyes of the ICD', as one cardiac electrophysiologist told me. This is done when the everyday cyborg undergoes medical interventions such as an MRI or radiotherapy. This was the case with Alfred, for example, when receiving treatment for his oesophageal cancer. The actual physical removal and replacement of the battery and the generator from the chest cavity itself is done every eight or so years depending on the amount of ICD activity in terms of pacing, cardioversion and shocks. Because David's ICD had only discharged a shock once and, as discussed above, he questioned whether it was appropriate, he had had discussions with his cardiologist about its removal. David, who was one of the 'oldest' cyborgs having received an ICD almost 20 years previously that was implanted into his stomach due to the size of the ICD at that time, discussed how the wires would be left should it ever be removed:

David: I mean, the ... the one I had in before, as I say, er, they ... they found it quite difficult to fit into my body, it was quite ... 
it was so big. Um, but the other thing is that I think when they took it out, I have a feeling that they weren't taking the wires out, um, because they'd been in there for so long and, er, the way that I remember the surgeon talking about it a few years ago ... er, the effect of stripping the wires from my ...

Gill: Yeah.

David: ... veins would be, er ... would be pretty traumatic and, um ...

Gill: Yeah.

David: ... so, you know, if it did ... if it ... if it was removed and wasn't replaced [the ICD], then I'd still have the, kind of, vestiges of it in my body still, um, I guess.

Norman's ICD was placed on the right-hand side of his chest and not the left due to his veins being blocked with infection. ${ }^{3}$ Norman's account of his infection highlights how important the wires are to the discharges of the shocks. Two cables with electrodes at the ends are worked through a vein, into the patient's heart, where they transmit electrical signals back to the ICD. As I suggested earlier, the wires can cause the surgeon significant problems entering them correctly into the heart, but once they are in, it is very difficult to remove the wires. Norman spoke about the infection that his ICD caused and the trouble getting the wires back out:

Norman: It took, it took, it was about ten days from having it, having it replaced, so-called, or put back in and the thing going into terrible infection. So, what they had to then do is to take it all out, everything out.

Gill: How did you feel about that?

Norman: Well it wasn't very nice, because they couldn't get the wire out. And they had to get the wire out from going through my groin to get it into the heart and pull the wire out that way, 'cause they couldn't get it out any other way.

Removing the wires is a procedure generally avoided because of the possibility of clots being formed and breaking free or as Neil said earlier, when drawing the analogy between his body and a ship, because of the 'gunk'.

None of the everyday cyborgs I spoke with had had the ICD removed despite some requesting it. If a cyborg is created by placing a cybernetic system into an organism, then it would seem plausible 
to suggest the cyborg identity is reversible when the cybernetic system is removed. It is taking the cybernetic out of the organism. There are pressing ethical questions about the ICD's removal during the dying process. It is the case that because of the ICD the everyday cyborg will not die from an SCA; however, the ICD can continue to shock the heart during the dying process when the heart ceases to function. Gaining consent to switch it off is important, therefore, as is making the everyday cyborg aware that this distressing situation may arise. I talked about this with only a few of the everyday cyborgs relying mostly on them to bring it up in conversation or at times when I could be confident it would not upset anyone present. This was not often, but had occurred in my interview with Graeme who had recalled a mostly benign experience of cyborgisation during which we discussed ownership of the ICD and then removal:

Graeme: Yeah, erm, I suppose [pause] ... I suppose ... it might be sensible at some stage, erm, to know who, erm, owns and controls the machine.

Gill: I guess. I guess so. I don't know.

Graeme: And ... and whether one does have, erm ... erm, the ... the authority to say to one's specialist, I want this thing either removed or ... or switched off.

Gill: In certain circumstances.

Graeme: Yes.

For Cathy, the ICD removal during the dying process was important for other family members. She thought it would be 'shocking', in this case, for her husband:

I don't know. For me it wouldn't matter to me because I won't be aware of it but potentially for people round about me that could be very alarming and distressing. I'm just thinking from Roger's point of view if he was with me, given how he feels. Even anybody that wasn't connected to me or didn't even know me if it happened in the street or whatever, I think that it would be shocking for them.

Anne, Timothy's daughter, spontaneously mentioned removing the ICD when I met with her and her husband Tom, during an interview about her father Timothy, who was not present:

Anne: Do you know what worries me and I've never thought about it, right, I don't know whether I saw this on 'Casualty' 
[a long-running UK drama series set in a hospital] one day, right, but I don't know if I want this to be on the thingy, right, but how does he [Timothy] die?

Gill: Yeah. That's a question, isn't it?

Anne: And I don't know if he's ever thought about that. I don't know if he's ever ... well how does he die? The thing goes off to start your heart. In fact, who was it ...

Tom: The brain would die. Does it not? Would it not be starved of the oxygen?

Anne: No, you ... it would start ... it would just shock you and shock you and shock you and shock you 'til somebody switched it off. Somebody ...

Tom: I think we should all get them fitted.

Anne: ... told me that. Aye, but there's going to come a point that you don't want to still be ... it's ... medically ...

Tom: They take it then ... at that stage, you'd be going in to the hospital and the doctor...

Anne: Yes, but how ... what kind of horrendous way ...

Tom: ... would disconnect that.

Anne: Aye. But how much of a horrendous ordeal is that going to be, 'til you ... 'til what? 'Til an ambulance arrives? 'Til they decide that it's shocked you 14 times and they've then got to get you to hospital, because you can't just ... I mean, who's going to switch it off? You don't just ...

Tom: Well it could be the next frigging morning before they switch it off.

Anne: Exactly. So, it's going to shock you all day ... aye.

In the UK, NICE has raised the importance of having such a discussion before implantation of the ICD and 'that careful, explicit and shared decision-making about the appropriate use of these technologies in the context of end-of-life care planning is important' (2014: 40-41). Indeed, in his second interview, John noted such information was available. However, he felt that 'there's a real reluctance of any of the medical staff, I think, to speak to people about the real downside of things, you know', and researchers have suggested similar views to those expressed by him (Russo, 2011). My reluctance to raise the issue during interviews attests to the sensitivities involved. With ICDs, associated vulnerabilities may relate 
to an alienation to the device being in the body as well as the cyborg being under the control of the ICD as opposed to being in control of it. Acclimatisation to the ICD enables it to be viewed as part of their body and a part of their routine day-to-day life, and it was unclear in the very few conversations with the everyday cyborgs about how they felt about permanent deactivation-ending the techno-organic hybrid life.

\section{Conclusions: the dys-appearance of flesh and machines}

To paraphrase Simone de Beauvoir, 'one is not born, but rather becomes an everyday cyborg'. There is a unique liminal depth to the bodily modifications - and breadth to the broader social life changes - caused by reliance on a cybernetic device. I have drawn on accounts of individuals and their significant others to show what it was like to acclimatise to a cybernetic device such as an ICD - to put into words what they felt was going on inside their bodies: in this case, the vulnerabilities caused by alienation from implantation and a reconciliation to possible activation. There is a love-hate relationship between the everyday cyborg and their cybernetic devices. On the one hand it can save their life but on the other it does so by producing a new vulnerability.

For most everyday cyborgs I spoke with, the ICD transitioned from an alien physically forced into their body breaching its integrity, to eventually settle not entirely under but not entirely on the skin. The ICD is out of reach of the everyday cyborg, yet can be felt on the inside, even when resting. The ICD casts a shadow, a silhouette, on the skin's surface and thus it can be felt and seen by the everyday cyborg. Its skin silhouette leaves not only a scar, but an imprint where the integrity of the body has been compromised. Usually, the body is an absent experience to the person in everyday living. Becoming a cyborg causes this taken-for-granted absence of the body to change. This is a second-order absence and is termed 'dys-appearance' (Leder, 1990: 91): in other words, a presence.

The area of the chest where the ICD exists becomes a focal point for the everyday cyborg. For the everyday cyborg, the absent 
absences of the body and organs are not static states but variable, for example, when the body heals the ICD becomes slowly enmeshed into the body, creating a more comfortable form of techno-organic hybridity. Everyday cyborgs live with a machine inside their bodies that they can feel from the inside out; there was a strong sensation of the ICD being inside the body. For the majority, most of the time the sensation was not dwelt upon and the body is, as Leder (1990) would suggest, an absence in the same way as the rest of the visceral is. Acclimatisation to hybridity occurs when the ICD's body presence becomes an absent absence, and the body returns to an absent state. These are variable processes and are always subject to change. Change can occur when the ICD defibrillates or shocks the cyborg's heart.

\section{Organic versus mechanical}

The technology is not organic, it is an alien intrusion and not seen as an actual part of them until, that is, it becomes a part of their 'body' (what they are) as well as a part of their subjectivity and beyond (who they are). The everyday cyborg can reinterpret the technology as transitioning from an alien intrusion to becoming a part of them; a part of their body as well as their life. In the case of device implantation, the transformation is through the device's alienation being recast as human. It is not that the human recipient becomes machine, therefore, but the machine that is humanised. It appeared important that part of the acclimation process was in accepting the hybrid body as the individual's new form of embodiment as a cyborg. While the organism becomes cybernetic, the cybernetic also becomes the organism. When organic hybrids are created through transplantation of non-human animal or human materials, the body and subjectivity is altered in light of the body's modification. Here, human subjectivity is not altered through the modification, as it would be if it were a transplant from an organic source. The ambiguous form of embodiment in the case of techno-organic hybridity such as everyday cyborgs does not mean that the subjectivity is altered due to the materiality that is implanted, but that the cybernetic technology is altered when implanted into the body. 
The ICD system becomes enmeshed into the body, but this does not mean that a simultaneous acceptance of the everyday cyborg's subjective 'part of me' will ensue. Enmeshment of the device in the body does not necessarily imply acceptance of the new cyborg subjectivity immediately follows. Almost all everyday cyborgs had experienced loss or change in some aspect of their previous life from their cardiac condition, whether it was their home, economic independence, employment, friends, self-confidence or mobility. The ICD did not and could not change the past, but what its functioning did 'for' them could be seen as a benefit. Becoming a techno-organic hybrid created through placing a cybernetic device in a person is not always straightforward. Acclimatisation to cyborg hybridity was challenging for some and overcoming the alien presence is facilitated by coming to accept it as a positive, allowing the everyday cyborg to live their life anew. In short, the changes to the body allow some to return to the life previously lost by their 'broken heart'.

Reaching the point when it is comfortable in being an everyday cyborg, and is a new state that is the end of the journey that began with the ICD being forced into a body which has little space for it. Acclimatisation, the act of getting used to an 'intruder' and the creation of the new cyborg hybridity, is a fluid and complex process. In some cases, acclimatisation can be uneventful, and the ICD is viewed by the everyday cyborg as a positive and is strongly connected with what it does for the individual. This is when the ICD recovers the previous identity of the everyday cyborg which was a subjectivity they had lost with the onset of disease or before the SCA. At such times, then, an ICD is said to be 'part of me' or 'it allows me to be who I am'. Both are powerful statements of acceptance when challenges to the body's integrity are overcome, and the altered subjectivity of the person to cyborg is beneficial.

\section{Autonomy and control}

Loved ones and significant others experienced a sense of relief that the ICD is a surveillance system, quite literally life insurance, bringing the emergency hospital room inside the cyborg's body. There are several important features of the ICD's C3I, however, that cause new vulnerabilities for the everyday cyborg. Control 
emerges as a particularly important dimension by creating vulnerability in two ways. The first is where the everyday cyborg cannot reach the ICD, resulting in the ICD being out of their physical control. Implantation necessarily causes vulnerability issues because the ICD is implanted and not physically accessible. This is a frustrating paradox in that while the ICD is so close within the cyborg (quite literally inside of them) at the same time, it is outwith their physical control. The second vulnerability results from their lack of control over the device. The ICD's autonomy diminishes the individual's autonomy over it. The ICD can function without a human operator and is capable of self-autonomous actions. The ICD has an element of control in the way that it can cause changes to the heart and its rhythm. The everyday cyborg is under the control of the ICD and is subjected to its actions, whether defined by them or others, as appropriate or not.

Technology often acts in uncertain and unpredictable ways, whether faults in the hardware with wires becoming loose or in the sensing ability of a device to react to what is deemed appropriate in terms of activity or appropriate levels. However, what seemed more disruptive was when the ICD was functioning appropriately and as it was intended to do by shocking the everyday cyborg's heart out of a potentially lethal heart rate. To reconcile the ways that cybernetic control is implemented within the everyday cyborg, the everyday cyborg reasserts their control by narrating how it was their actions that had caused the ICD to discharge. It was common during interviews that a reason was offered as to how the everyday cyborg caused the device to activate whether it was by excessive exercise, consumption or concern. Blaming their actions thus reinserts their control over the autonomy of the device, and is an activity that as human beings we are relatively accomplished at doing:

Nursing ill-will towards an enemy, cursing an errant computer, kicking a flat tyre, or pitying oneself ... will not necessarily effect any change in the behaviour of the object or other, but may reverse one's experience of one's relationship with it. One becomes, imaginatively and retrospectively, the determining subject of the events that reduced on to the status of the object ... as actors rather than acted upon, as authors of meaning rather than victims of circumstance.

(Jackson, 2002: 338) 


\section{Notes}

1 Stewart had an ICD and like most ICDs it has the ability to pace his heart, before then emitting a small series of shocks known as cardioversion, preparing for shock therapy.

2 www2.warwick.ac.uk/fac/med/research/hsri/emergencycare/ prehospitalcare/jrcalcstakeholderwebsite/guidelines/the_implantable_ cardioverter_defibrillator_icd_2006.pdf) (accessed April 2020).

3 He was typical of those that were said to be able to feel their device inside the body: 'Yeah, the device is there, you can feel it ... And then I can feel here, there's a wire.' When I asked whether he 'twiddled' with the wire, he responded that he hadn't, although this has been found to be an issue in the medical literature (Nicholson, Tuohy and Tilkemeier, 2003). 